\title{
GEOGRAFIA E DEPENDÊNCIA: O DIÁLOGO ENTRE MILTON SANTOS E RUY MAURO MARINI A PARTIR DA TEORIA DO SUBIMPERIALISMO
}

\section{Thiago Machado*}

A tradução aqui apresentada do texto de Milton Santos intitulado Sub-imperialism as Viewed by a Geographer, publicado em 1975, possibilita resgatar o debate entre a Geografia e a teoria da dependência, especialmente por dar visibilidade ao diálogo entre Milton Santos e o sociólogo brasileiro Ruy Mauro Marini. Em que pesem os conflitos no seio da formulação da teoria da dependência, o que conferiu a Marini certo aspecto marginal no pensamento social brasileiro, estabelecer uma visão geográfica do conceito de subimperialismo parece responder aos anseios de Milton Santos em produzir categorias analíticas que superem a mera importação de teorias formuladas nos países centrais. Além disso, oferece o retrato de uma época em que a discussão do desenvolvimento, do subdesenvolvimento e do imperialismo estava na ordem do dia nas ciências sociais, inclusive na Geografia brasileira, contexto que contribuiu para a sua virada crítica ao final da década de 1970.

O texto está inserido numa coletânea publicada pela Universidade de Toronto como produto final do período em que Milton Santos ocupou uma cátedra na Faculdade de Artes e Ciências daquela universidade nomeada "The Latin American in Residence Chair"1 no ano letivo de 1972-1973, um dos tantos centros onde ele trabalhou em

*Doutorando pelo Programa de Pós-Graduação em Geografia da Universidade Federal Fluminense e Bolsista CAPES. E-mail: machado.ta@gmail.com

'SANTOS, Milton Santos. Underdevelopment and Poverty: A Geographer's View, University of Toronto, 1975 decorrência do exílio. Sob o título Underdevelopment and Poverty: A Geographer's View, o trabalho é composto por uma série de quatro artigos: Brazil: a Underdeveloped and Industrialized Country, Development: Theories and Poverty, Sub-imperialism as Viewed by a Geographer e City Growth and Space Organization: Incomplete Metropolis in Latin America.

Apesar disso, o texto em questão é resultado da participação de Milton Santos na conferência "Dependência Externa e Problemas de Desenvolvimento na América Latina e Caribe", ocorrida em abril de 1972 na Universidade de Toronto, momento no qual o geógrafo brasileiro ainda fazia parte do Departamento de Estudos Urbanos e Planejamento do Massachusetts Institute of Technology (MIT), nos Estados Unidos. Com a participação de vários intelectuais latino-americanos, como Aníbal Quijano, Octávio lanni e Ruy Mauro Marini, o evento era organizado de maneira que cada palestrante contasse com um comentador do seu trabalho. Desse modo, ficou a cargo de Milton Santos comentar a palestra de Ruy Mauro Marini intitulada Subimperialismo Brasileiro na América Latina, para a qual foi tomado como base o artigo de Marini publicado na Monthly Review em fevereiro daquele mesmo ano, Brazilian Imperialism².

Adiscussão do subimperialismoestavaplenamenteem acordo com os temas tratados por Milton Santos àquela

${ }^{2}$ MARIANI, Ruy Mauro. Brazilian Subimperialism. Monthly Review, vol. 23, n 9, 1972 


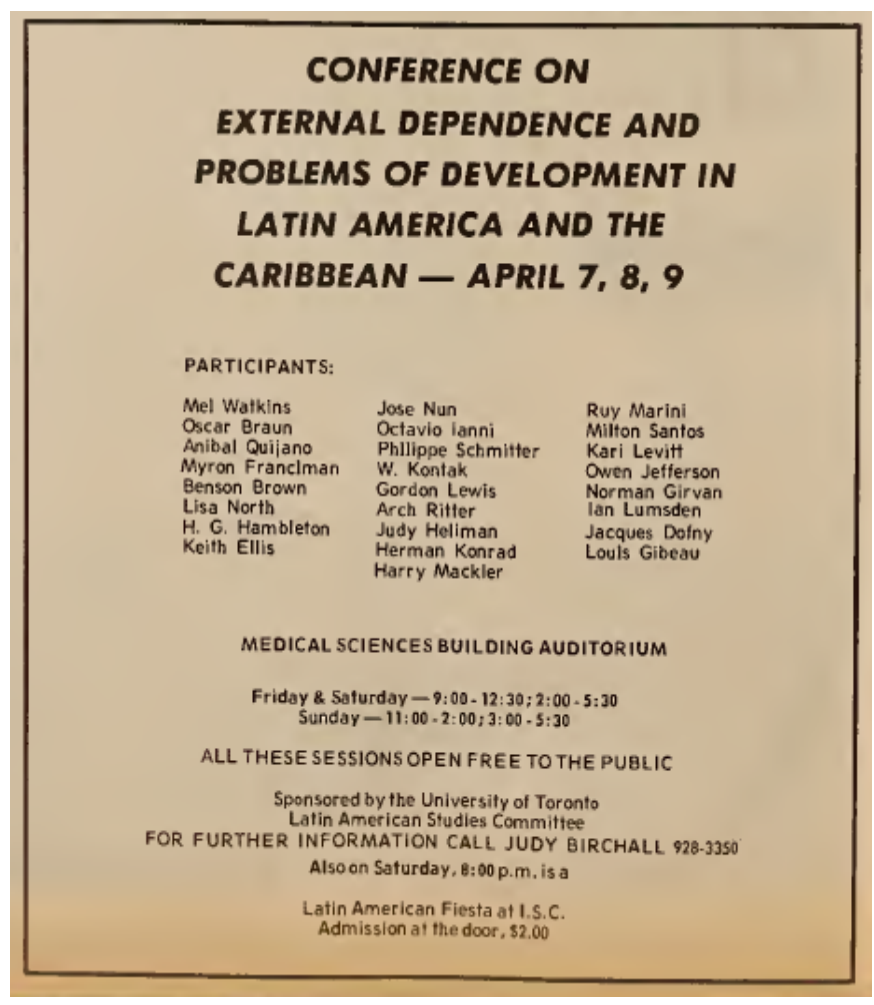

Divulgação da Conferência na revista The Varsity, 29 de março de 1972, Toronto, Canadá

época, sobretudo no que diz respeito à urbanização dos países subdesenvolvidos e à especificidade do espaço nesses países frente aos processos de modernização capitalista e de planejamento econômico. Desse modo, a redação do texto a partir do seu diálogo com Ruy Mauro Marini, em conjunto com os demais artigos da publicação de 1975, imprime o conjunto de debates que encontram uma forma melhor acabada na publicação na França de O Espaço Dividido ${ }^{3}$, também em 1975. Neste livro, há trechos de transcrição quase completa do artigo aqui traduzido e, é possível discutir a partir de tal obra, a assimilação ou não das teses da "dialética da dependência" e do "subimperialismo" na discussão que Milton Santos promove sobre os circuitos superior e inferior da economia urbana ao dar especial atenção aos setores monopolistas, à necessidade de exportação e à dependência tecnológica das indústrias nos países subdesenvolvidos.

\section{0 ambiente intelectual do debate da Dependência}

O debate travado nas ciências sociais latinoamericanas entre as décadas de 1950 e 1970 privilegiava a discussão sobre a condição de subdesenvolvimento e dependência dos países da América Latina frente à divisão

3SANTOS, Milton Santos. L'espace Partagé: les deux circuits de l'economie urbaine des pays sous-développés. Editions Librairies Techniques, M. Th. Génin, Paris, França, 1975. internacional do trabalho e as práticas imperialistas do pós-guerra. Inaugurado a partir da publicação pela CEPAL em 1949 do trabalho de autoria de Raul Prebisch, Estudio Económico de America Latina ${ }^{4}$, a discussão do desenvolvimento brasileiro e latino-americano era um grande e rico campo de disputa de narrativas e estratégias envolto no ambiente da industrialização nacional via substituição de importações e das disputas políticoideológicas da Guerra Fria.

Especificamente no que se refere ao contexto brasileiro, Ricardo Bielschowsky ${ }^{5}$ distingue cinco correntes de pensamento estruturadas durante a transição do modelo agroexportador para a economia urbano-industrial: o desenvolvimentismo do setor privado, representado por Roberto Simonsen; o desenvolvimentismo "não-nacionalista", liderado por Roberto Campos; o desenvolvimentismo nacionalista de Rômulo de Almeida e, posteriormente, Celso Furtado; a corrente liberal que defendia a "vocação agrária", liderada por Eugenio Gudin; e à esquerda a corrente formada pelos intelectuais do Partido Comunista Brasileiro (PCB), centrados na ideia da etapa "democrático-burguesa" de transição ao socialismo.

Dentre tais correntes de pensamento emerge a organização de grupos de intelectuais a partir dos quais a formulação de teorias e interpretações da realidade

${ }^{4}$ PREBISCH, Raul. Estudio Economico de America Latina 1949. Nueva York: Departamento de Asuntos Economicos, 1951.

${ }^{5}$ BIELSCHOWSKY, Ricardo Bielschowsky. Pensamento Econômico Brasileiro: o ciclo ideológico do desenvolvimentismo. Rio de Janeiro: Contraponto, 1995. 
brasileira são empreendidas, principalmente vinculadas à estratégia nacional-desenvolvimentista. Nesse sentido, os embates entre os teóricos da CEPAL (Comissão Econômica para a América Latina das Nações Unidas), do ISEB (Instituto Superior de Estudos Brasileiros) e, posteriormente, da Escola de Sociologia da USP formam o corpo teórico que leva à teoria da dependência.

A CEPAL de Raul Prebisch, Celso Furtado, Aníbal Pinto, Maria da Conceição Tavares e Oswaldo Sunkel denuncia a deterioração dos termos de troca nas relações centroperiferia da divisão internacional do trabalho, ficando conhecida como a escola do estruturalismo cepalino. Os intelectuais do ISEB, como Alberto Guerreiro Ramos, Ignácio Rangel, Rômulo de Almeida, Nelson Werneck Sodré e Hélio Jaguaribe, dentre outros, compartilhavam boa parte do diagnóstico cepalino e, em geral, defendiam a industrialização nacional como uma estratégia de superação do subdesenvolvimento. Destacam-se, assim, como nacionalistas com vistas à formação de uma burguesia industrial capaz de, a partir de um pacto com as camadas populares, enfrentarem o desafio de mudar a posição do país na divisão internacional do trabalho.

Pouco mais de uma década depois surge aquilo que ficaria conhecido como Escola de Sociologia da USP, centrada na figura do sociólogo Florestan Fernandes ${ }^{6}$, mas cujo protagonista da polêmica em torno da teoria da dependência passaria a ser Fernando Henrique Cardoso. Este, ao criticar a narrativa nacional-desenvolvimentista predominante, busca destacar as relações de classes sociais internas ao desenvolvimento do capitalismo brasileiro, defendendo a incapacidade da formação de uma burguesia nacional que levasse adiante a estratégia desenvolvimentista e a possibilidade de desenvolvimento por meio da poupança externa, naquilo que seria uma forma de dependência associada via o investimento estrangeiro direto. O livro que Fernando Henrique Cardoso escreve em parceria com o sociólogo chileno Enzo Falleto em 1969, Dependência e Desenvolvimento na América Latina ${ }^{7}$, passa a ser reconhecido como o grande referencial da chamada Teoria da Dependência, de forma que boa parte do debate de então fique enviesado ao ofuscar uma das principais correntes de pensamento à época.

Centro difusor de uma das interpretações mais originais, porém submetida à censura e ao ofuscamento durante muitas décadas, a POLOP (Política Operária) era um grupo que pretendia criar as condições para a construção de um partido revolucionário no país e, portanto, tinha uma posição radical à esquerda da

${ }^{6}$ Florestan Fernandes foi o primeiro intelectual latino-americano a ocupar a cátedra voltada à América Latina na Universidade de Toronto no período letivo de 19691970. Parte do seu trabalho aí produzido foi publicado no livro "Capitalismo Dependente e as Classes Sociais na América Latina", Rio de Janeiro: Zahar Editores, 1972

${ }^{7}$ CARDOSO, Fernando Henrique; FALETTO, Enzo Faletto. Dependência e Desenvolvimento na América Latina. Rio de Janeiro: Zahar, 1969. formulação do $\mathrm{PCB}^{8}$ (Partido Comunista Brasileiro) ao negar as condições de uma etapa democrático-burguesa rumo ao socialismo no Brasil. Sob a liderança de Ruy Mauro Marini, contava com nomes como Vânia Bambirra e Theotônio dos Santos, além de estreita colaboração com o economista alemão André Gunder Frank, figura de proa no debate da dependência. 0 seu artigo $O$ Desenvolvimento do Subdesenvolvimento ${ }^{9}$, publicado em 1966, foi tanto um dos pontos de partida, mas também o alvo de muitas das críticas por conta do seu entendimento sobre o capitalismo colonial na América Latina.

Todos esses distintos grupos intelectuais são contemporâneos de um período em que havia acirrada disputa ideológica entre o capitalismo e o socialismo não apenas no campo das ideias, mas como sistemas político-econômicos viáveis, especialmente após o sucesso da Revolução Cubana em 1959, a qual não só ampliou os ânimos revolucionários na América Latina, como também provocou a reação conservadora que levou aos golpes de Estado continente afora. Desse modo, o debate da dependência acabou por ser desenvolvido no exílio de vários desses intelectuais, o que de certa forma contribuiu para a colaboração internacional e para a reflexão da América Latina como um todo, influenciando substancialmente a experiência intelectual de Ruy Mauro Marini.

\section{Ruy Mauro Marini e a Teoria do Subimperialismo}

0 economista Bresser-Pereira ${ }^{10}$ defende haver, portanto, três principais correntes da teoria da dependência: a nacional-dependente, a da dependência associada e a da superexploração do trabalho. A primeira vinculada à CEPAL e ao ISEB, a segunda à Escola de Sociologia da USP, mas principalmente a Fernando Henrique Cardoso, e a última a Ruy Mauro Marini e seus companheiros da POLOP. Contudo, boa parte da narrativa empregada por teóricos de peso vinculados ao nacional desenvolvimentismo, como Celso Furtado, privilegiava o debate do subdesenvolvimento, de modo que aos olhos de hoje a disputa em torno da dependência tenha se dado efetivamente entre as formulações personalizadas nas figuras de Fernando Henrique Cardoso e Ruy Mauro

${ }^{8} \mathrm{O}$ livro organizado por Luiz Bernardo Pericás e Licoln Secco, "Intérpretes do Brasil: clássicos, rebeldes e renegados", tenta resgatar intérpretes nacionais para além dos consagrados, o que inclui aqueles vinculados ao PCB, tais como Octávio Brandão, Astrogildo Pereira e Leôncio Basbaum. A obra de outro ilustre filiado ao PCB, Caio Prado Jr., polemiza com a linha central do partido sobre o Brasil e sua evolução econômica, "A Revolução Brasileira", cuja última edição foi publicada em conjunto com "A Questão Agrária" pela Boitempo em 2014

${ }^{9}$ Andre Gunder Frank, "The Development of the Underdevelopment", em Monthly Review, vol. 18, n 4, September 1966.

${ }^{10}$ BRESSER-PEREIRA, Luiz Carlos. Do ISEB e da CEPAL à Teoria da Dependência. In: TOLEDO, Caio Navarro (Org.). Intelectuais e Política no Brasil: a experiência do ISEB. São Paulo: Editora Revan, 2005. 
Marini ${ }^{11}$.

Se a proposição de Cardoso apontava para a industrialização viabilizada pela poupança externa e, de certo modo, uma posição resignada frente à dependência, a formulação de Marini era anticapitalista e anti-imperialista, pois defendia que a superação da condição de dependência não poderia ocorrer nos marcos do capitalismo. Tal posição era sustentada por duas teorias principais: a da superexploração do trabalho e a do subimperialismo, ambas constituindo o eixo da dialética da dependência ${ }^{12}$.

Analisando o processo histórico da estratégia de substituição de importações no marco do pósguerra, Marini afirmava que a industrialização latinoamericana [e, sobretudo, a brasileira] integrava-se aos setores monopolistas do imperialismo de modo que as suas economias permaneciam voltadas para o setor externo, ao passo que a fragilidade do mercado interno pressionava os salários para níveis abaixo da capacidade de reprodução da força de trabalho. Ou seja, se o capital industrial em solo brasileiro não dependia dos seus trabalhadores para que estes consumissem os bens industriais aqui produzidos, lhe era permitido pressionar para baixo os salários ao ponto que ficassem abaixo do nível necessário ao consumo básico médio dos trabalhadores.

Somado à superexploração estava a própria dependência tecnológica, pois para que ocorresse ganhos de produtividade necessários à competição no mercado internacional, fazia-se urgente o incremento na composição orgânica do capital por meio da importação de maquinário, o que ampliava o endividamento em moeda estrangeira e a própria necessidade de exportação para equilibrar a balança comercial. Para tanto, o Estado exercia um papel crucial ao subsidiar os setores exportadores, financiando diretamente os setores monopolistas, e ao garantir o investimento em infraestrutura e indústria de base que permitiam a formação bruta de capital. É na conjunção dos aspectos econômicos e políticos que Marini forja a teoria do subimperialismo, pois a perspectiva de resolver o problema da acumulação de capital estava atrelada ao projeto geopolítico regional do governo ditatorial brasileiro sobre o restante da América Latina, de forma que realizasse um subimperialismo ou um imperialismo de "segundo grau" subordinado ao capital monopolista internacional.
A dependência no contexto brasileiro estaria, desse modo, por trás do golpe de 1964, pois a estratégia de João Goulart para a crise de acumulação, cujas reformas de base centravam-se no fortalecimento do mercado interno, não agradavam ao capital monopolista, dado que sua produção centrada em bens de consumo duráveis encontrava dificuldades de demanda efetiva no mercado interno, além de que o aumento dos salários levaria a uma redução da taxa de mais-valor. A ditadura militar teria oferecido, portanto, a viabilidade aos setores monopolistas ao agravar a dependência por meio de uma acumulação de capital crescente ao mesmo tempo em que ocorriam arrochos salariais e ampliava-se a desigualdade econômica no país. O subimperialismo estava atrelado a um tipo de capitalismo autoritário, implicando em subordinação econômica, concentração de renda e estratégia geopolítica expansiva.

Afınado ao trotskismo e ao pensamento de Rosa Luxemburgo, Ruy Mauro Marini alicerçava tal formulação do subimperialismo no desenvolvimento desigual e combinado do capitalismo e na necessidade de exportação de capitais, tal como defendia a ideia de revolução permanente, por meio da qual caberia aos trabalhadores, frente a uma burguesia nacional débil, empreender os esforços para a superação da condição de dependência ${ }^{13}$. Por conta desse projeto político subjacente Marini esteve sempre engajado politicamente, de modo que depois do golpe, que interrompeu as atividades da POLOP, passou a integrar o MIR (Movimento de Esquerda Revolucionária) durante o seu exílio no Chile, onde chegou a fazer parte do comitê central e participou ativamente do ambiente que levou ao poder o socialismo democrático de Salvador Allende. Com o golpe de setembro de 1973 parte para o México onde permanece até 1985 , quando retorna ao Brasil.

A sua produção principal sobre o subimperialismo brasileiro, a partir da qual Milton Santos estabelece a sua análise, conjuga os trabalhos 'Interdependência' Brasileira e Integração Imperialista ${ }^{14}$, publicado na Monthly Review em 1965, Subdesenvolvimento e Revolução ${ }^{15}$, originalmente publicado no México em 1969; e Subimperialismo Brasileiro ${ }^{16}$, também publicado na Monthly Review em 1973. A importância desse conceito tem sido atestada recentemente pelo resgate realizado por autores contemporâneos, como Raul

\footnotetext{
${ }^{11} \mathrm{O}$ acirramento da discussão entre tais perspectivas se deu com a publicação por parte de Fernando Henrique Cardoso e José Serra do artigo As Desventuras da Dialética da Dependência, Estudos CEBRAP, n² 23, 1978. A resposta de Ruy Mauro Marini veio no artigo Las Razones del Neodesarrollismo (respuesta a F. H. Cardoso y J. Serra), Revista Mexicana de Sociología, vol. 40, nº extraordinário, 1978. Apesar y J. Serra), Revista Mexicana de Sociologia, vol. 40, no extraordinario, 1978. Apesar
do combinado, Fernando Henrique Cardoso e José Serra não publicaram nos Estudos CEBRAP a resposta de Marini, tal como este o fez ao publicar ambos artigos na Revista Mexicana de Sociología, da qual era editor.

${ }^{12}$ MARIANI, Ruy Mauro. Dialéctica de la dependência. México D.F.: Ediciones Era, 1973.
}

${ }^{13}$ ALMEYRA, Guillermo. "Ruy Mauro Marini”, em Pericás e Secco (Orgs.) Intérpretes
do Brasil: clássicos, rebeldes e renegados. (São Paulo, Boitempo, 2014).
${ }^{14 M A R I A N I, ~ R u y ~ M a u r o . ~ B r a z i l i a n ~ I n t e r d e p e n d e n c e ~ a n d ~ I m p e r i a l i s t ~ I n t e g r a t i o n ~}$
Monthly Review, vol. 17, n 7, 1966.
${ }^{15}$ MARIANI, Ruy Mauro. Subdesarrollo y revolución. México D.F.: Siglo XXI, 1969.
${ }^{16}$ MARIANI, Ruy Mauro. Brazilian Imperialism. Monthly Review, vol. 23, nº 9, 1972. 
Zibechi $^{17}$ e Virgínia Fontes ${ }^{18}$, tratando do protagonismo regional do Brasil e a força de setores da sua economia em empreender a política imperialista de exportação de capitais, a qual ganhou novo fôlego nos últimos 15 anos e merece ser analisada sob o quadro amplo do desenvolvimento brasileiro atual.

\section{Milton Santos e os Países Subdesenvolvidos Industrializados}

Como toda uma geração de intelectuais brasileiros, Milton Santos também desenvolveu parte importante do seu pensamento no exílio. Preso em 1964 quando presidia na Bahia a Comissão Estadual de Planejamento Econômico (CEP), onde estabeleceu contato aproximado com membros do Partido Comunista e com isebianos como Guerreiro Ramos e Candido Mendes ${ }^{19}$, Santos partiu para o exílio na França ao conseguir com os amigos franceses uma posição na Universidade de Toulouse. De lá parte para a Universidade de Bourdeux, e, posteriormente, para a Sorbonne, onde permanece até 1971. Depois do período na França é convidado como pesquisador visitante no Massachusetts Institute of Technology (MIT), onde avança na redação do "O Espaço Dividido", a qual é concluída no seu período em Toronto (1972-73) ${ }^{20}$.

A década de 1970 é bastante profícua ao seu trabalho de compreensão da realidade do Terceiro Mundo ao circular não somente por universidades dos EUA e da Europa, mas também da América Latina (Universidade de Lima, no Perú; Universidade Central da Venezuela) e da África (Universidade de Dar-es-Salaam), além do seu trabalho de consultor na Organização Internacional do Trabalho (OIT) e na Organização dos Estados Americanos (OEA), que lhe permitiu realizar missões técnicas em diversos países africanos e latino-americanos. A sua análise do subdesenvolvimento centra-se nos processos de urbanização e sua crítica ao planejamento econômico destaca a fragilidade do transplante teórico para os países subdesenvolvidos de ideias concebidas segundo o desenvolvimento econômico e espacial europeu e norteamericano.

É nesse contexto que está o trabalho publicado no Canadá, o qual, enquanto parte integrante do processo de pesquisa e redação de "O Espaço Dividido", está preocupado com a realidade social e econômica dos países pobres, partindo, porém, de um olhar espacial, das

${ }^{17} \mathrm{ZIBECHI}$, Raul. Brasil Potencia: entre la integración regional y um nuevo imperialismo. Bogotá: Ediciones desde abajo, 2012.

${ }^{18}$ FONTES, Virgínia Fontes. O Brasil e o Capital-Imperialismo: teoria e história. Rio de Janeiro: Editora UFRJ, 2010.

${ }^{19} \mathrm{CONTEL}$, Fábio Betioli. Milton Santos. In: Pericás e Secco (Orgs.) Intérpretes do Brasil: clássicos, rebeldes e renegados. (São Paulo, Boitempo, 2014).

${ }^{20}$ lbidem, p. 398 realidades urbanas e regionais. Desse modo, o seu diálogo com Ruy Mauro Marini tem a preocupação de inserir no debate tal dimensão espacial, a qual já vinha sofrendo o seu escrutínio crítico em decorrência das teorias da economia espacial que serviam para instrumentalizar o planejamento econômico nos países pobres da América Latina e África. É ao partir dessas premissas, portanto, que, ao tratar do subimperialismo de Marini, Milton Santos o põe em equivalência à noção de país subdesenvolvido industrializado.

Esse termo teria sido empregado pela primeira vez em 1971 no seu livro "Les Villes du Tiers Monde"21 e voltaria a ser utilizado para uma análise da realidade brasileira em palestra proferida no período em que esteve em Toronto como professor visitante, cujo texto transcrito faz parte da coletânea publicada em 1975, posteriormente traduzido como um dos capítulos do "Espaço e Sociedade"22, publicado em 1979. Milton Santos defende que o conceito de país subdesenvolvido industrializado viria resolver um problema da "velha taxonomia político-geográfica ${ }^{23}$ que põe de um lado os países industrializados e do outro os países subdesenvolvidos, também chamados de "nãoindustrializados". De forma que a industrialização fosse tomada como condição de desenvolvimento, haveria agora países em que a industrialização existia apesar, ou mesmo reforçava, o subdesenvolvimento, cujos exemplos mais eminentes seriam àquela época Brasil, Argentina, México, Índia, Egito e, talvez, África do Sul.

Os países subdesenvolvidos industrializados seriam marcados por uma industrialização dependente que se desdobraria em três aspectos: dependência tecnológica, dependência das formas de organização da produção (monopólios) e dependência nas formas de organização espacial (concentrada e pontual). 0 aspecto espacial é destacado, inclusive ao nível da definição do próprio conceito de país subdesenvolvido industrializado, já que para o autor não basta a caracterização de matiz econômica, mas, sobretudo, o aspecto da rede urbana, pois "[o] nível de importância e complexidade alcançado pelas suas metrópoles determina e espelha o nível de industrialização de um país subdesenvolvido"24. Por conta disso, não bastam a quantificação e as tipologias industriais, o que interessa à análise é a integração funcional e as conexões geográficas que permitem ir além dos enclaves industriais e permite a identificação do nível de aglomeração polarizadora que determina a industrialização de um país subdesenvolvido.

${ }^{21}$ SANTOS, Milton. Les Villes du Tiers Monde. Paris: Editions N. Th. Genin, Librairies Techniques, 1971

${ }^{22}$ SANTOS, Milton. Brasil: país subdesenvolvido industrializado. Capítulo IX de Espaço e Sociedade, Petrópolis: Vozes, 1979 (2º Edição, 1982).

${ }^{23}$ Essa conceituação está inserida no mesmo contexto da análise do Sistema-Mundo, a partir da qual o sistema de Estados seria distinguido em centro, semi-periferia e periferia. Immanuel Wallerstein, "The Politics of the World-Economy: the States, the movement and the civilisations", New York: University of Cambridge, 1984.

${ }^{24}$ SANTOS, Milton. Espaço e Sociedade. 1982, p. 106 
A caracterização geral é, assim, resumida numa modernização e industrialização punctiformes, dependentes e voltadas para o exterior.

Sem o interesse de aqui esgotar a discussão empreendida pelo autor na época, destacamos a centralidade do conceito de período tecnológico, o qual precede a formulação daquele de meio técnico-científico informacional ${ }^{25}$. Considerava-se que o período pósguerra seria desfavorável à industrialização dos países subdesenvolvidos, tanto pelo domínio da tecnologia, situada nos centros econômicos, quanto pela lógica organizacional da produção em larga escala que favorecia a concentração e o monopólio. Os países subdesenvolvidos industrializados foram, portanto, aqueles que conseguiram antecipar a sua industrialização, ainda que em marcos iniciais, para o período de transição do século XIX para o século XX.

Países como Brasil, México, Índia, dentre outros, teriam se industrializado em duas fases distintas do período tecnológico,emquena primeiraasindústrias seorganizam espacialmente nas aglomerações que já ostentam as infraestruturas de transporte e de comércio, numa rede urbana de estrutura piramidal (no caso do Brasil podemos falar da "urbanização em arquipélagos"), ao passo que na segunda fase as condições dependem cada vez mais de decisões externas ao país e, sob a tutela do investimento estatal, se voltam à exportação. A formação de enclaves produtivos, dirigidos pelo estrangeiro e "autônomos" do resto da região ou do país reforçam o caráter punctiforme e dependente da industrialização.

O papel do Estado é destacado ao reforçar os fatores de concentração por privilegiar os setores monopolistas com os subsídios à exportação, enquanto os fatores de dispersão são restringidos pela capacidade limitada de consumo via mercado interno, decorrente do achatamento do poder de compra e as pressões sobre a massa salarial.

Isto explica porque, em uma situação de subimperialismo, há um perfeito sinônimo entre por um lado, monopólios e multinacionais, e por outro lado, macrocefalia e suas consequências: desemprego,subemprego, marginalidade, terciarização e o assim chamado "dualismo"26.

Assim como defendido no início do capítulo sexto de "O Espaço Dividido"27, o Estado apresenta-se como aliado do circuito moderno da economia nos países subdesenvolvidos. Aqui Milton Santos corrobora com
Ruy Mauro Marini ao identificar o papel do Estado sua tarefa em três níveis, no subsídio direto do setor exportador, no investimento em infraestrutura e bens de capital que garantam os investimentos e na produção de bens intermediários. Nessa mesma lógica, a teoria da superexploração de Marini é consoante à teoria dos dois circuitos da economia urbana de Milton Santos. 0 processo de modernização da economia, por meio da industrialização voltada para fora, é viabilizada pela superexploração da força de trabalho que passa a ter de recorrer ao circuito inferior da economia urbana para acessar os bens e serviços. Por isso que a ambos circuitos, superior e inferior, são efeitos da modernização no contexto subdesenvolvido.

\begin{abstract}
Os pobres, na visão do nosso estudo, são aqueles que não têm acesso, de modo regular, aos bens de consumo corrente considerados como o mínimo indispensável numa certa sociedade. Muito raramente têm acesso ao crédito institucional e representam o essencial da clientela dos pequenos estabelecimentos comerciais e artesanais, que oferecem crédito pessoal a taxas usurárias. Trata-se, em geral, dos não-empregados e dos subempregados, mas também dos assalariados que recebem muito pouco. ${ }^{28}$
\end{abstract}

Por fim, destaca-se o potencial interpretativo desse período da obra de Milton Santos sobre a realidade do Brasil, inserindo-se, desse modo, na tradição do pensamento social brasileiro que empreendeu grande esforço para compreender as grandes transformações que o país e a América Latina passavam no pós-guerra, período ainda muito importante contemporaneamente, pois crucial para muito dos fatos que se sucederam nas décadas seguintes.

Uma análise mais minuciosa desse diálogo entre ambos intelectuais se faz, contudo, urgente para que melhor identifiquemos a trajetória da Geografia no pensamento social brasileiro, bem como as condições contemporâneas sejam situadas em relação às teorias formuladas num período que se impunha de forma dramática. Esperamos, finalmente, que essa tradução possa colaborar para que o debate do subimperialismo possa ser ampliado na Geografia, além de atentar para a complexidade da obra de Milton Santos, em especial naquilo que se refere à sua reflexão sobre o Brasil.

\footnotetext{
${ }^{25}$ Para a discussão desses conceitos em Milton Santos ver O Período Tecnológico e os Estudos Geográficos, em Revista do Departamento de Geografia da USP, vol. 4 1985; e Espaço \& Método, São Paulo: Nobel, 1985. 